
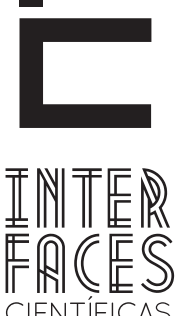

CIENTÍFICAS

HUMANASE SOCIAIS

ISSN IMPRESSO 2316-3348

E-ISSN 2316-3801

DOI - 10.17564/2316-3801.2018v6n3p47-58

\title{
TENDÊNCIAS PRIVATISTAS NA POĹTITCA DE EXPANSÃ̃ DO ENSINO SUPERIOR DE 1990 A 2015 NO BRASIL
}

PRIVATIVE TRENDS IN THE POLICY OF EXPANDING HIGHER EDUCATION FROM 1990 TO 2015 IN BRAZIL

TENDENCIAS PRIVATISTAS EN LA POLÍTICA DE EXPANSIÓN DE LA ENSEÑANZA SUPERIOR DE 1990 A 2015 EN BRASIL

\section{RESUMO}

Este trabalho analisa as continuidades e alterações na política de expansão do ensino superior em 26 anos (1990-2015), dos quais os 13 últimos foram marcados pela chegada ao poder de governos considerados de esquerda. A partir de revisões bibliográficas, bem como de análises de documentos e dados produzidos pelo governo federal, com destaque para o censo da educação superior, foi possível averiguar como as propostas de reforma do Estado, orientadas pelos ideais neoliberais adotados na década de 1990 no Brasil, consolidaram e aprofundaram o modelo privatista de educação superior já em curso no país desde a reforma universitária de 1968. Os resultados gerais do estudo expostos neste artigo permitem compreender que a lógica de desresponsabilização do Estado por meio da transfe- rência do protagonismo da expansão dessa modalidade de ensino para a iniciativa privada não foi rompida nos governos petistas. Apesar disso, a sistematização e a análise dos dados coletados do censo demonstram que há algumas mudanças relevantes na condução da política a partir de 2003, especialmente em relação à retomada na criação de instituições públicas, com redução proporcional do crescimento do número de matrículas privadas na comparação com o crescimento de matrículas públicas.

\section{PALAVRAS-CHAVE}

Ensino superior. Expansão. Privatização. 


\section{ABSTRACT}

This paper analyzes the continuities and changes in the policy of expansion of higher education in 26 years (1990-2015), of which the last 13 were marked by the arrival of governments considered from left come to power. Based on bibliographic reviews, as well as analyzes of documents and data produced by the federal government, with emphasis on the census of higher education, it was possible to find out how the State reform proposals, guided by the neoliberal ideals adopted in the 90's in Brazil, consolidated and deepened of privatization model of higher education that has been underway in the country since the university reform of 1968 . The general results of the study presented in this article allow us to understand that the logic of removing responsibility of State and of

\section{RESUMEN}

Este trabajo analiza las continuidades y alteraciones en la política de expansión de la enseñanza superior en 26 años (1990-2015), de los cuales los 13 últimos fueron marcados por la llegada de gobiernos considerados de izquierda al poder. A partir de revisiones bibliográficas, así como de análisis de documentos y datos producidos por el gobierno federal, con destaque para el censo de la educación superior, fue posible averiguar cómo las propuestas de reforma del Estado, orientadas por los ideales neoliberales adoptados en la década de 1990 en Brasil, consolidaron y profundizaron el modelo privatista de educación superior ya en curso en el país desde la reforma universitaria de 1968. Los resultados generales del estudio expuestos en este artículo permiten comprender que la lógica de desresponsabilización del Estado por me- transferring the protagonism of the expansion of this modality Private initiative was not broken in the PT governments. Nevertheless, the systematization and analysis of the data collected from the census show that there are some relevant changes in the conduct of the policy since 2003, especially in relation to the resumption of public institutions, with a proportional reduction in the growth of the number of private enrollments in the comparison with the growth of public enrollments.

\section{KEYWORDS}

Higher education. Expansion. Privatization. dio de la transferencia del protagonismo de la expansión de esa modalidad de la enseñanza para la iniciativa privada no se rompió en los gobiernos petistas. Sim embargo de ello, la sistematización y análisis de los datos recolectados del censo demuestran que hay algunos cambios relevantes en la conducción de la política a partir de 2003, especialmente en relación a la reanudación en la creación de instituciones públicas, con reducción proporcional del crecimiento del número de matrículas privadas en comparación con el crecimiento de las matrículas públicas.

\section{PALABRAS CLAVE}

Enseñanza superior. Expansión. Privatización. 


\section{INTRODUCÇÃO}

A trajetória da educação superior no Brasil carrega consigo as marcas do tipo dependente de capitalismo aqui experimentado, fator que sustentou a importação de conhecimentos, políticas, propostas de gestão, metas e modelos europeus de universidade (LIMA, 2007; SOLANO, 2013). Aliás, como salientou Fernandes (1975), a universidade no Brasil resultou da conglomeração das antigas escolas superiores, voltando-se historicamente para a formação e qualificação das elites econômicas nacionais.

O fato é que, para além da relevância histórica da reforma universitária promovida no âmago da ditadura militar em 1968, responsável pela instalação do modelo de universidade vigente no país atualmente, um período que merece ênfase são os anos de 1990. A última década do século $X X$ possui uma importância fundamental para a compreensão das bases ideológicas e sociopolíticas que sustentaram o "processo de democratização" do acesso a esse nível de ensino nos anos 2000. Como se sabe, é no decorrer desse período que se dá a implantação mais efetiva de boa parte do receituário neoliberal pactuado pelo Consenso de Washington de 1989, com destaque para os dois mandatos de Fernando Henrique Cardoso.

Tal receituário, cujos ingredientes e processos serão abordados no decorrer deste trabalho, impactou diretamente os caminhos, as finalidades e as ações desenvolvidas na política de educação superior, com atenção especial para o aumento da participação da iniciativa privada em um claro movimento de desresponsabilização do Estado. Obviamente, por trás de tal condução, há uma série de pressupostos ideológicos que sustentou e ainda sustenta o processo que Lima (2007, p. 57) denominou de "contra-reforma da educação superior" no Brasil.

Os efeitos desse movimento, no entanto, não se restringiram aos anos de 1990, tendo condicionado alguns dos caminhos que foram traçados para o ensino universitário no início do século XXI, principal- mente no que diz respeito à ampliação da oferta de vagas conduzida por uma série de programas e legislações criados nos governos de Luiz Inácio Lula da Silva e Dilma Rousseff. Como será demonstrado, apesar do crescimento e do fortalecimento das instituições públicas de ensino superior, a política conduzida pelos governos petistas na área não rompeu com o caráter privatista em vigor há mais de 40 anos no país.

\section{CAMINHOS DA EXPANSÃO DA EDUCAÇ̃̃O SUPERIOR NO BRASIL}

Desde a criação das universidades no início do século XX, a educação superior no Brasil esteve fundada basicamente na oferta de cursos por instituições públicas, financiadas diretamente pelo Estado e instituições privadas confessionais, sem fins lucrativos (especialmente de origem católica e, em único um caso, protestante). De acordo com Calderón (2000), até 1968, existiam no Brasil cerca de 31 universidades públicas e 12 de caráter confessional, sendo que havia uma grande preocupação com a qualidade do ensino ofertado, inclusive nas atividades de pesquisa e pós-graduação, que muitas cultivam até os dias atuais. Segundo Durham e Sampaio (1995), todavia, sempre esteve presente uma grande importância desse setor privado, que concentrou cerca de $44 \%$ das matrículas entre os anos de 1930 e 1964.

Durante a década de 1960, construiu-se um grande movimento nacional pela ampliação de vagas no ensino superior, dado o crescente número de "excedentes" - alunos que tinham conseguido ingressar na universidade, mas não estudavam pela ausência de vagas. Para enfrentar tal déficit que, em cerca de uma década (1960-1971), saltou de 28.728 para 161.176 alunos excedentes, o governo militar permitiu a abertura de escolas superiores privadas e a autorização de ampliação das vagas das instituições existentes sem controle efetivo dos critérios de qualidade (CALDERÓN, 2000). 
Nesse sentido, o autor identifica a criação e consolidação de dois padrões de oferta de educação superior a partir desse período: um na universidade pública elitista, que manteve mais ou menos estável a oferta de vagas na graduação, tendo institucionalizado a pesquisa e a pós-graduação voltadas para a produção de conhecimento; outro, nas instituições e escolas privadas isoladas, com padrão de qualidade não mensurado com precisão e basicamente voltadas para a transmissão de conhecimentos.

Após a reforma universitária de 1968, estima-se que foram criadas mais de 600 escolas isoladas pelo país até 1975 , as quais, a partir da década de 1980 e mais precisamente nos anos de 1990, articularam-se em federações e escolas integradas, transformando-se no que Calderón (2000) denominou de "universidades mercantis" - instituições particulares com explícitos fins lucrativos. Durham e Sampaio (1995) demonstram, por meio de dados coletados no Ministério da Educação, que o percentual de matrículas em instituições privadas saltou de 43,8\% em 1965 para algo em torno de 62\% em 1990.

Já sob a proposta de adequação do país às exigências da economia de mercado globalizada, esse processo de expansão da rede privada mercantil foi fortalecido e ratificado no decorrer da década de 1990, nos governos Collor de Mello, Itamar Franco e Fernando Henrique Cardoso. No caso do governo Collor (19901992), Lima (2007) enumera seis ações principais que poderiam ser destacadas como referências na iniciativa de reformulação do ensino superior brasileiro, embora nem todas tenham se efetivado por força dos movimentos de resistência dos trabalhadores da educação e dos estudantes:

1 - Apresentação de uma Proposta de Emenda Constitucional (PEC) com a finalidade de fixar um percentual do orçamento das universidades que poderia ser usado para pagamento de salários, custeio e investimentos, o que afetaria diretamente a autonomia dessas instituições, garantida pelos artigos 206 e 207 da Constituição;
2 - Proposta de Emenda Constitucional que retirava as condições de servidor público dos trabalhadores da educação;

3 - Desnacionalização de setores estratégicos do país, inclusive no tocante à questão da ciência e tecnologia;

4 - Tentativa de extinção da Coordenação de Aperfeiçoamento do Pessoal de Nível Superior (CAPES) e do Instituto Nacional de Estudos e Pesquisas Educacionais Anísio Teixeira (INEP), com mudanças na formação, desvinculando-a da pesquisa e da pós-graduação e dando foco à preparação para o mercado de trabalho;

5 - Não cumprimento do percentual mínimo de $18 \%$ de investimento em educação; 6 - Favorecimento da expansão do ensino privado, inclusive em divergência com as posições do Conselho Federal de Educação na autorização e reconhecimento de cursos.

Em relação ao governo de Itamar Franco, Lima (2007) prossegue sua argumentação informando que não houve rompimento com o caráter privatizante reforçado pelo antecessor. Nessa direção, destaca-se a sanção da Lei no 8.958 de 1994, a qual regulamenta as relações entre instituições federais e fundações privadas para a captação de recursos e financiamento de projetos de ensino, pesquisa e extensão. Apesar de muitas ações regulatórias e com caráter privatista, Martins (2000) destaca, todavia, o crescimento incipiente do número total de vagas no ensino superior nos governos de Collor e Itamar Franco entre os anos de 1990 e 1993, cerca 3,5\% (de 1.540 .080 vagas para 1.594.668, mantendo as proporções de vagas privadas na casa dos 60\%).

A partir de 1994 e, principalmente, de 1995, com o governo de Fernando Henrique Cardoso, volta a ocorrer um crescimento significativo no número de instituições, em especial privadas e de matrículas. Embora em proporção muito menor do que o ocorri- 
do no período de ditadura militar (entre 1960 e 1980), em que se experimentou um aumento de $500 \%$ no número total de matrículas e $800 \%$ somente no setor privado (SAMPAIO, 2011), no primeiro mandato de Fernando Henrique Cardoso (FHC) (1995-1998) as taxas de matrícula voltaram a aumentar de maneira significativa, cerca de $15 \%$ nas instituições públicas e $25 \%$ nas privadas (MARTINS, 2000).

Nesse contexto, chama atenção o fato de que, durante o primeiro mandato do governo de Fernando Henrique Cardoso, não foi criada universidade pública federal alguma, enquanto 80 novos estabelecimentos privados (entre universidades, faculdades integradas e estabelecimentos isolados) se constituíram nesse período. Como se verifica, além da retomada do modelo privatista de educação superior propagado pela reforma universitária de 1968, os governos da década de 1990, essencialmente o de FHC, promoveram uma estagnação na oferta dessa modalidade de ensino em instituições públicas federais e um incentivo às instituições privadas, principalmente as instituições mercantis.

$\mathrm{Na}$ realidade, a educação de uma maneira geral e, destacadamente, o ensino superior, em tempos de avalanche neoliberal, passou a se tornar um campo bastante lucrativo para o capital. Como observou Calderón (2000), a constituição e o fortalecimento de um verdadeiro mercado de ensino ressignificou a possibilidade de compreensão do ensino universitário enquanto direito social, transformando-o em um direito de consumo. Há, inevitavelmente, um desvio na compreensão de cidadão, que deixa de exigir diretamente do Estado a participação nos bens sociais e intelectuais construídos coletivamente para realizá-los via mercado. Trata-se de um caminho bastante distinto daquele que alimentou o movimento estudantil na década de 1960 e os movimentos sociais que deflagraram a conquista dos direitos sociais assegurados constitucionalmente em 1988.

Por trás desse movimento, o que se verifica, porém, é uma ideologia bastante estruturada e que foi capaz de alimentar uma série de modificações nas concepções sobre os papéis e as funções do Estado na década de 1990. Foi durante os mandatos de
FHC que tais visões de mundo foram sistematizadas e implantadas organicamente sob os moldes de um projeto de governo, materializado em um conjunto de diretrizes e ações que promoveu uma reforma do aparelho estatal. Os fundamentos que sustentaram tal reforma são esclarecedores para compreender por que o modelo privatista de educação superior já em curso no país desde os anos de 1960 não apenas se manteve como foi fortalecido e aprimorado no decorrer dos anos de 1990.

\section{PRINCÍPIOS DA REFORMA DO ESTADO E EDUCAÇÃO SUPERIOR NOS ANOS DE 1990}

Com o objetivo de promover uma profunda "reconstrução da administração pública" no Brasil, a equipe do Ministério da Administração Federal e da Reforma do Estado (MARE) do governo FHC, com destaque para a atuação do Ministro Luiz Carlos Bresser Pereira, elaborou um Plano Diretor da Reforma do Aparelho do Estado, aprovado em 1995, o qual, entre outros pontos, buscava estabelecer "bases modernas e racionais" para um modelo gerencial de administração, voltado para o controle de resultados, a produtividade, a descentralização e a concepção de cidadão cliente (BRASIL, 1995).

A justificativa de apresentação de tal plano, que abarcava em si outras duas reformas - uma administrativa, com a flexibilização da estabilidade no serviço público e outra previdenciária -, estava galgada na concepção de que a crise econômica que se arrastava desde o final da ditadura militar era fruto de distorções nas relações entre Estado e sociedade. Dessa maneira, o governo argumenta que o Estado teria se desviado de suas funções precípuas (reguladoras) para assumir uma sobrecarga de demandas sociais e para atuar diretamente na esfera produtiva, fatores que teriam levado ao déficit fiscal e ao esgotamento do modelo produtivo.

No Brasil, embora esteja presente desde os anos 70, a crise do Estado somente se tornará clara a partir da segunda metade dos anos 80 . Suas manifestações mais evidentes são a própria crise fiscal e o esgotamento da estratégia de substituição de importações, que se 
inserem num contexto mais amplo de superação das formas de intervenção econômica e social do Estado. Adicionalmente, o aparelho do Estado concentra e centraliza funções, e se caracteriza pela rigidez dos procedimentos e pelo excesso de normas e regulamentos. (BRASIL, 1995, p. 11).

A rigor, a crise econômica é tida como fruto de uma crise do próprio modelo de Estado, o que exigiria o redimensionamento das suas tarefas e papéis para a superação das dificuldades. Nesse processo, há o reconhecimento de três formas de administração pública: patrimonialista, burocrática e a gerencial, esta proposta pelo plano, como já foi citado. As duas primeiras, nessa ordem, representariam modelos ultrapassados em que: 1- o Estado, nepotista e patrimonialista, seria a extensão do poder do soberano; 2- ou o Estado, na tentativa de romper com o primeiro modelo, estaria voltado para si, perdendo a capacidade de servir os cidadãos - essencialmente em sociedades complexas e com muitas demandas sociais.

0 modelo gerencial, por sua vez, teria emergido na segunda metade do século XX como resposta à expansão das funções econômicas e sociais do Estado, ao desenvolvimento tecnológico e à globalização. Sua bases estariam fundadas na noção de governança, entendida como a capacidade de implementar políticas públicas de maneira eficiente (com menor custo e maior qualidade). Não obstante, a concepção gerencial, com foco na eficiência, propõe a adoção de princípios de mercado (administração de empresas) no âmbito da administração pública, entre eles: a competição entre unidades prestadoras de serviços, 0 controle de resultados, a transferência de responsabilidades para a iniciativa privada.

Destaca-se que as proposições do MARE não se autodeclaravam de orientação neoliberal (considerada uma perspectiva utópica), uma vez que o ministério reconheceria a importância da intervenção estatal, principalmente no campo social. Contudo, as políticas sociais, dotadas de interesse e de função públicos, seriam serviços não exclusivos do Estado, devendo ser implementadas com participação e apoio da sociedade civil e do mercado. É justamente aqui que reside a chave para a compreensão dos rumos assumidos pela educação superior no Brasil.

Em seus estudos sobre política educacional, Peroni (2003) e Peroni e Adrião (2004) ressaltam as três frentes de desresponsabilização do Estado, são elas: privatização, terceirização e publicização. 0 ensino superior sofreu, na década de 1990, ofensivas por meio dessas três estratégias. Primeiro pela retomada do crescimento de instituições privadas, segundo pela terceirização de diversas tarefas administrativas no interior dos órgãos públicos (inclusive com a extinção de cargos) e terceiro pela adoção de modelos gerenciais de gestão, inclusive com a diversificação das fontes de financiamento.

Nas palavras de Barroso (2013), porém, todas essas estratégias podem ser compreendidas como formas de privatização, já que esse conceito envolve, de maneira geral, um declínio na provisão estatal com diversas variações, as quais abarcam desde as parcerias público-privadas, até a transferência completa dos serviços para a iniciativa privada. No caso do ensino superior brasileiro, não se pode dizer que ocorreu um desmantelamento completo da rede pública, até porque há nesse processo um conjunto de forças de resistência. 0 que se observa, seguindo as reflexões de Solano (2013), é uma redução progressiva da atuação direta do Estado e a incorporação de uma lógica produtiva nos estabelecimentos públicos existentes.

Destarte, na perspectiva de se adequar a tais formulações, Peroni (2002) reitera que a reforma promovida na educação nos anos de 1990 se desenvolveu por meio de duas iniciativas paralelas: 1 - um projeto global, sistematizado no corpo da Lei de Diretrizes e Bases da Educação de 1996 (LDB); 2 - um conjunto de planos setoriais e decretos.

Essas iniciativas e as perdas e conquistas que representaram foram delineadas em quadros explicativos no trabalho de Lima (2007), mas cabe destacar as seguintes alterações entre o projeto de lei (PL) inicial da LDB (1.258 de 1988) e o PL 101 de 1996, aprovado sob a forma de Lei no 9.394: retirada da concepção de educação voltada para a prática social e a produção de conhe- 
cimento; redução da obrigação do Estado de oferecer acesso e permanência em todos os níveis - manteve-se apenas o ensino fundamental e (progressivamente) o ensino médio; retirada da questão da gratuidade das escolas públicas do texto; diversificação dos tipos de instituições de ensino superior, com consequente retirada da indissociabilidade entre ensino, pesquisa e extensão (mantida apenas nas universidades).

No caso do conjunto de planos setoriais e decretos, chamam atenção os vetos promovidos no Plano Nacional de Educação de 2001. Dentre eles os seguintes podem ser enfatizados: garantia de uma proporção mínima de $40 \%$ de participação do setor público no conjunto de vagas ofertadas no ensino superior; retirada da proposta de criação de um Fundo de Manutenção e Desenvolvimento da Educação Superior, constituído com ao menos $75 \%$ de recursos da União; garantia de crédito educativo para pelo menos 30\% da população matriculada no setor privado; ampliação dos recursos destinados à pesquisa, triplicando o valor correte à época; implantação de planos gerais de carreira para os profissionais da área técnica e administrativa no prazo de um ano; elevação dos gastos com educação para no mínimo $7 \%$ do Produto Interno Bruto (PIB) na década; garantia de financiamento dos três entes federativos com valores por aluno, tomando como referência padrões mínimos de qualidade (BRASIL, 2001).

Na realidade, essas duas referências centrais (LDB e PNE), além de importantes decretos e leis específicos sancionados no período correspondente aos dois mandatos de $\mathrm{FHC}^{33}$, demonstram uma postura do governo no sentido de retirar o máximo de obrigações possíveis do Estado em relação à educação, principalmente no que tange ao financiamento e à disponibilização direta de serviços.

Por outro lado, promoveu-se um processo de desburocratização, facilitação e incentivo à oferta de vagas em instituições privadas - filantrópicas/confessionais e mercantis. Nesse contexto, a educação passa a ser compreendida como um campo passível

3 Para descrição e análise detalhada de cada um desses documentos legais, ver Lima (2007) de lucratividade e, portanto, competitivo, devendo ser gerida diretamente pelo mercado ou pelo "quase-mercado" ou "terceiro setor" (SILVA, 2000; MONTAÑO, 2014) - instituições prestadoras de serviços de interesse público, com financiamento público, mas natureza e lógica de funcionamento privadas.

Calderón (2000), ratificando essa compreensão, assevera a importância da década de 1990 para consolidação da lógica mercantil no ensino universitário, inclusive pela agressividade e pela profissionalização das propagandas criadas pelas universidades mercantis para atrair consumidores. Segundo o autor, esse movimento só foi viável com as "vantagens competitivas" abertas pela Constituição Federal de 1998 e a LDB de 1996, que eliminaram os entraves burocráticos via Conselho Federal de Educação para abertura, fechamento e definição de vagas dos cursos. 0 acesso ao ensino superior consolidou-se como um bem de consumo (BARROSO, 2013), algo que, como será analisado a seguir, não foi substancialmente alterado nos anos seguintes após a chegada de um governo considerado de esquerda ao poder em 2003.

\section{CONTINUIDADES E MUDANÇAS NAS POLÍTICAS DE EXPANSÃO DO ENSINO SUPERIOR NA DÉCADA DE 1990 E NOS ANOS 2000}

Para Cislaghi e Silva (2012), é preciso problematizar se o crescimento do acesso ao ensino superior no Brasil constitui-se como um processo de "massificação" ou "democratização", em especial com a criação de um conjunto de programas governamentais após 2003. Conquanto se possam notar algumas mudanças importantes na condução do acesso ao ensino universitário com a eleição de Luiz Inácio Lula da Silva, não seria possível dizer que houve um rompimento da política educacional brasileira com as proposições de organismos multilaterais, como o Banco Mundial. Na realidade, a ampliação do número de matrículas, desde os anos de 1990, busca atender às requisições 
dos capitais internacional e nacional que culpavam o baixo nível de qualificação dos trabalhadores brasileiros como entrave para o aumento da produtividade e o enfrentamento da pobreza.

Assim como ocorreu na década de 1990, os governos brasileiros dos últimos 13 anos, com o objetivo de atingir as metas definidas pelo Banco Mundial (1994 e 2002), vêm implantando algumas medidas que se coadunam com a lógica gerencial definida na proposta de reforma do Estado de 1995, entre elas: aumento da relação professor/aluno nas instituições públicas; diminuição dos índices de evasão e repetência; mobilidade estudantil; parcerias, incentivos fiscais e financiamento do setor privado na oferta de cursos em nível de terceiro grau; ampliação do ensino a distância; regulamentação de outras fontes de receita fora do fundo público para financiamento das universidades públicas. Algumas delas já foram abordadas no item anterior, mas o fato é que essas medidas não apenas se mantiveram, também foram ampliadas nos governos do Partido dos Trabalhadores (PT) nos anos 2000, conforme salienta Lima (2007).

Nessa conjuntura, o crescimento do Fundo de Financiamento Estudantil (FIES) e a criação do PROUNI ${ }^{4}$ merecem atenção por se constituírem em mecanismos de transferência direta ou indireta de recursos públicos para instituições privadas, muitas delas mercantis. Em termos de proporção, por exemplo, esses programas contribuíram para a manutenção e ligeira ampliação do predomínio das instituições privadas em relação ao total de matrículas nos ensino superior presencial. Em 1990, tais instituições respondiam por $62,4 \%$ do total de matrículas, algo que foi ampliado para $69,8 \%$ em 2002, último ano do governo de FHC. Em 2010, fim do mandato de Lula, esse percentual cresceu para 73,2\%, com ligeiro recuo em 2015 (72,2\%), último ano completo do governo de Dilma Rousseff. Mais informações podem ser observadas nas duas tabelas abaixo:

40 programa Universidade para Todos oferece bolsas de até $100 \%$ em instituições privadas de educação superior, possibilitando, em contrapartida, uma série de isenções de impostos.

Tabela 1 - Crescimento do número de matrículas no ensino superior presencial até o final do mandato de FHC

\begin{tabular}{llllll}
\hline \multirow{2}{*}{ Tipo de instituição } & \multicolumn{5}{c}{ Ano } \\
\cline { 2 - 6 } & 1990 & 1995 & 1998 & 2002 & $\%$ \\
\hline Instituições privadas & 961.455 & 1.059 .163 & 1.321 .229 & 2.428 .258 & 153 \\
Instituições públicas & 603.601 & 700.540 & 804.729 & 1.051 .655 & 74 \\
Total & 1.540 .080 & 1.759 .703 & 2.125 .958 & 3.479 .913 & 126 \\
\hline
\end{tabular}

Fonte: INEP (2017) (elaboração própria).

Tabela 2 - Crescimento do número de matrículas no ensino superior presencial nos governos Lula e Dilma

\begin{tabular}{lccccc}
\hline \multirow{2}{*}{ Tipo de instituição } & \multicolumn{5}{c}{ Ano } \\
\cline { 2 - 6 } & 2003 & 2006 & 2010 & 2015 & $\%$ \\
\hline Instituições privadas & 2.750 .652 & 3.467 .342 & 3.987 .424 & 4.809 .793 & 75 \\
Instituições públicas & 1.136 .370 & 1.209 .304 & 1.461 .696 & 1.823 .752 & 60 \\
Total & 3.887 .022 & 4.676 .646 & 5.449 .120 & 6.663 .545 & 71 \\
\hline
\end{tabular}

Fonte: INEP (2017) (elaboração própria). 
Como se verifica, em termos percentuais em relação ao que se recebeu de matrículas, o crescimento em 13 anos de "governos neoliberais" foi mais significativo do que o experimentado no mesmo lapso temporal dos governos petistas. Ainda em termos percentuais, a intensidade do crescimento das matrículas privadas se mostrou consideravelmente mais forte entre 1990 e 2002 (153\%), mais do que o dobro de 2003 a 2015 (75\%). Entretanto, em números absolutos, a era Lula-Dilma possibilitou bem mais matrículas, tanto privadas (2.509.141 contra 1.466.803) quanto públicas (687.382 contra 448.054). Isso representa, comparando os 13 anos de governos de cada uma das tabelas acima, que os governos petistas criaram $40,4 \%$ mais vagas privadas do que os antecessores e $53,4 \%$ mais vagas públicas.

Ao seguir a argumentação já exposta neste trabaIho, não há um rompimento com a lógica privatista em curso desde 1968, intensificada nos anos 1990 do mesmo século. Tal constatação não invalida a existência de algumas modificações relevantes, como uma retomada considerável do papel das instituições públicas na educação superior. Mesmo com a manutenção do predomínio mercantil, além de as matrículas na rede pública terem crescido percentualmente mais do que as privadas nos governos do PT, também foram criadas mais instituições públicas.

Tabela 3 - Crescimento das instituições de ensino superior até o final do mandato de FHC

\begin{tabular}{llllll}
\hline \multirow{2}{*}{ Tipo de instituição } & \multicolumn{5}{c}{ Ano } \\
\cline { 2 - 6 } & 1990 & 1995 & 1998 & 2002 & $\%$ \\
\hline Instituições privadas & 696 & 684 & 764 & 1.442 & 107 \\
Instituições públicas & 222 & 210 & 209 & 195 & -12 \\
Total & 918 & 894 & 973 & 1.637 & 78 \\
\hline
\end{tabular}

Fonte: INEP (2017) (elaboração própria).

Tabela 4 - Crescimento das instituições de ensino superior nos governos Lula e Dilma

\begin{tabular}{cccccc}
\hline \multirow{2}{*}{ Tipo de instituição } & \multicolumn{5}{c}{ Ano } \\
\cline { 2 - 6 } & 2003 & 2006 & 2010 & 2015 & $\%$ \\
\hline Instituições privadas & 1.652 & 2.022 & 2.100 & 2.069 & 25 \\
Instituições públicas & 207 & 248 & 278 & 295 & 43 \\
Total & 1.859 & 2.270 & 2.378 & 2.364 & 27 \\
\hline
\end{tabular}

Fonte: INEP (2017) (elaboração própria). 
Os dados acima demonstram, possivelmente, em relação aos dois períodos analisados neste item, os aspectos mais discrepantes. Em primeiro lugar, o número de instituições privadas dobrou em 13 anos de governos Collor, Itamar Franco e FHC; nos governos Lula e Dilma, o crescimento manteve-se na casa dos $25 \%$. Obviamente há, nesses períodos, como já foi ressaltado anteriormente, um movimento importante de fusão de instituições isoladas e centros universitários, os quais foram se transformando em universidades em busca da autonomia didático-pedagógica garantida pela Constituição Federal de 1988 e pela LDB de 1996.

Em segundo, e talvez o mais relevante, verifica-se o crescimento bem mais alto, em termos absolutos e percentuais, das instituições públicas nos governos Lula e Dilma. Cabe reiterar que muitas dessas instituições (universidades e institutos federais) possuem caráter multicampi, com uma capilaridade bem considerável em direção aos municípios mais interioranos. Em relação à redução de instituições entre 1990 e 2002, deve-se sublinhar também o processo de incorporação de escolas isoladas às universidades e a participação incipiente do governo federal na criação de novos órgãos, ficando a cargo dos estados e municípios o desempenho de tal papel.

\section{CONSIDERAÇÕES FINAIS}

Ao considerar as mudanças promovidas no papel no Estado no decorrer da década de 1990 , sistematizadas na proposta de reforma encaminhada pelo MARE e aprovada em 1995, este trabalho buscou resgatar como tais alterações causaram impacto na política de expansão do acesso à educação superior brasileira. Política esta cujo processo de privatização, iniciado ainda no período ditatorial, intensificou-se com a adoção dos ideais neoliberais de desresponsabilização do Estado nos governos de Collor, Itamar Franco e, principalmente, FHC. Esse movimento, expresso na valorização das parcerias público-privadas e na proliferação das universidades mercantis, mante- ve-se no decorrer dos anos 2000 com a chegada dos governos de Lula e Dilma.

A análise dos dados do Censo da Educação Superior entre os anos de 1990 e 2015 (INEP, 2017) permitiu demonstrar que, apesar de certas continuidades na condução geral da política - por exemplo, a predominância do setor privado na oferta de matrículas -, algumas modificações foram promovidas no decorrer dos governos petistas, em especial no tocante à criação de instituições e vagas públicas. Nesse quadro, para além da concepção dos Institutos Federais de Ciência e Tecnologia, Cislaghi e Silva (2012) enfatizam a função desempenhada pelo REUNI (Programa de Apoio a Planos de Reestruturação e Expansão das Universidades Federais).

Caberia acentuar ainda em relação ao acesso, especialmente da população mais pobre, que a aprovação da Lei 12.711 de $2012^{5}$, estabelecendo o sistema de cotas, bem como o fortalecimento do Exame $\mathrm{Na}$ cional do Ensino Médio (ENEM) e a criação de um Sistema Unificado de Seleção (SISU) se apresentam como iniciativas importantes. Esses programas, como já demonstrou o FONAPRACE (2011), têm promovido uma mudança significativa no perfil dos estudantes das instituições federais de educação, o que sinaliza um avanço relevante, mas também um grande desafio na garantia da qualidade da educação.

Nada disso deve fazer esquecer, contudo, que a maioria dos jovens de camadas populares ainda não frequenta o ensino superior em razão da predominância do setor privado na oferta de vagas, apesar da grande capacidade ociosa das instituições mercantis ou filantrópicas. Todos os dados e discussões trazidos e analisados neste texto demonstram que os governos analisados, em que pese aos avanços relatados, aprofundaram o padrão de política de educação superior implementado pelas reformulações promovidas no contexto de reforma do Estado dos anos de 1990.

5 Essa legislação estabelece que $50 \%$ de todas as vagas ofertadas pela rede federal devem ser reservadas para estudantes oriundos de escolas públicas, dos quais metade deve possuir renda per capita de até um salário mínimo e meio. Fica garantida ainda, no interior desses $50 \%$, uma proporção de reserva para negros, pardos, índios e deficientes equivalente ao último censo demográfico. 


\section{REFERÊNCIAS}

BANCO MUNDIAL. La enseñaza superior: las lecciones derivadas de La experiência. EUA: Banco Internacional de Reconstrução e Fomento, 1994.

\section{BANCO MUNDIAL. Construir sociedades}

de conocimiento: nuevos desafios para $L a$ Educacíon terciaria. EUA: Banco Internacional de Reconstrução e Fomento, 2002.

BARROSO, J. Autonomia das escolas: entre o público e o privado. In: PERONI, V. (Org.). Redefinições das fronteiras entre o público e o privado: implicações para a democratização da educação. Brasília: Liber Livro, 2013. p.48-57.

\section{BRASIL. Plano Diretor da Reforma do Aparelho do}

Estado, 1995. Disponível em: <www.bresserpereira. org.br/documents/mare/planodiretor/planodiretor. pdf>. Acesso em: 16 maio 2017.

BRASIL. Lei $\mathbf{1 0 . 1 7 2}$ de 2001 - Aprova o Plano Nacional de educação e dá outras providências. Disponível em: <http://www.planalto.gov.br/ccivil_03/leis/leis_2001/ l10172.htm>. Acesso em: 16 maio 2017.

CALDERÓN, A.G. Universidades mercantis: a institucionalização do mercado universitário em questão. São Paulo em perspectiva, v.14, n.1, p.61-72, 2000.

CISLAGHI, J.; SILVA, M. O Plano Nacional de Assistência Estudantil e o Reuni: ampliação de vagas versus garantia de permanência. Ser Social, Brasília, v.14, n.31, p.489-512, 2012.

DURHAM, E.; SAMPAIO, H. 0 ensino privado no Brasil: documento de trabalho do Nupes. São Paulo: USP, n.3, 1995.

Recebido em: 20 de Junho de 2017

Avaliado em: 4 de Julho de 2017

Aceito em: 4 de Julho de 2017
FLORESTAN, F. A universidade brasileira: reforma ou revolução? São Paulo: Alfa ômega, 1975.

FONAPRACE. Perfil socioeconômico e cultural dos estudantes das universidades federais brasileiras. Brasília: FONAPRACE, 2011.

LIMA, K. Contra-reforma da educação superior: de FHC a Lula. São Paulo: Xamã, 2007.

MARTINS, C. O ensino superior brasileiro nos anos 90. São Paulo em perspectiva, v.14, n.1, p.41-60, 2000.

MONTAÑO, C. 0 canto da sereia: crítica à ideologia e aos projetos do terceiro setor. São Paulo: Cortez, 2014.

PERONI, V. Política educacional e o papel do Estado no Brasil dos anos 1990. São Paulo: Xamã, 2003.

PERONI, V.; ADRIÃO, T. 0 público e o provado na educação: interfaces entre Estado e sociedade. São Paulo: Xamã, 2004.

SAMPAIO, H. O setor privado de ensino superior no Brasil: continuidades e transformações. Revista Ensino Superior Unicamp, v.4, p.28-43, 2011.

SOLANO, C.H. As políticas educacionais gerencialistas e o PDE-Escola. In: RODRIGUES, R. (Org.). Educação escolar no século XXI. Juiz de Fora: UFJF, 2013. p.79-97.

1 Doutorando em Políticas Sociais pela Universidade Estadual do Norte Fluminense - UENF; Mestre em Serviço Social pela Universidade do Estado do Rio de Janeiro - UERJ. E-mail: jonisfelippe@gmail.com

2 Doutora em Educação pela Universidade Federal Fluminense - UFF; Professora associada da área de Política e Gestão Educacional da Universidade Estadual do Norte Fluminense - UENF. E-mail: r.maldonado@globo.com.br 
